\title{
APLICAÇÃO DO DIREITO DA CONCORRÊNCIA NA UNIÃO EUROPÉIA E O PROTOCOLO DE FORTALEZA PARA O MERCOSUL
}

\section{APPLICATION OF THE COMPETITION RIGHT IN THE EUROPEAN UNION AND THE FORTALEZA PROTOCOL FOR MERCOSUL}

\author{
Martha Asunción Enríquez Prado"
}

\begin{abstract}
Resumo: A abertura da economia mundial exige competitividade do mercado nacional e internacional. Nesse compasso, a defesa da concorrência constitui pilar fundamental no desenvolvimento econômico, social e cultural de países ou blocos regionais. Contudo, é preciso criar uma cultura de concorrência na sociedade e nos governantes, entender que aplicar uma correta política de defesa da concorrência é o único meio para o crescimento econômico, social e cultural de uma sociedade. Governos e sociedade devem envidar todo esforço e habilidade para tal fim. Defendese a concorrência como garantia para os operadores do comércio, pelas vantagens de concorrer em igualdade de condições, em mercados em que os consumidores elegem produtos de melhor qualidade a preços mais acessíveis. Todo processo de integração econômica deve adotar medidas de defesa da concorrência que garantam segurança jurídica nas relações de mercado, assegurando desenvolvimento econômico com existência digna para os cidadãos.
\end{abstract}

Palavras-chave: Direito da concorrência. União Européia. MERCOSUL. Desenvolvimento econômico. Protocolo de Fortaleza.

Abstract: The opening of the world economy requires competitiveness
of national and international markets. Thus, the defense of competition
constitutes a fundamental element in the social, cultural and economic
development of countries or regional groups. However, it is necessary to
create a competition culture both in the society and in governments so
that they understand that applying a correct defense policy is the only
way for social, cultural and economic growth of a society. Government
and society should mobilize every effort and capacity for such an aim.
Competition is claimed as a guarantee for traders due to the advantages
of competing on equal terms in markets where consumers choose the

"Professora de Direito Internacional e Comunitário, na graduação e pós-graduação da Universidade Estadual de Londrina - UEL. Doutora pela PUC/SP. Pós/doutora pela Universidade Complutense de Madri. 
products that offer best price and quality. Every process of economic integration should adopt measures to defend competition that guarantee legal safety in market relations, assuring economic development with proper life for citizens.

Keywords: Competition right. European Uniono. MERCOSUL. Economic development. Fortaleza Protocol.

\section{INTRODUÇÃO}

A nova realidade exige a adequação de condutas dos agentes econômicos de países em desenvolvimento, para enfrentar o desafio do comércio global, porque a abertura à concorrência de setores, antes controlada pelo poder público, o desenvolvimento de novas tecnologias e a liberalização do comércio internacional representam um caminho sem retorno.

Este artigo mostra a experiência da União Européia na aplicação de normas de defesa da concorrência e a necessidade de blocos econômicos, como o MERCOSUL, se aparelharem de normas e instituições supranacionais para a integração efetiva entre os Estados-Membros.

A União Européia estabeleceu uma importante política econômica de livre mercado, liberalizando mercados, tradicionalmente monopolísticos, como alguns serviços públicos, em desvantagem de concorrer com países e setores da iniciativa privada, que oferecem melhores produtos, a preços competitivos e com benefícios diretos para os consumidores.

Acertou a UE ao incorporar normas de defesa da concorrência, no tratado de fundação, inibindo assim, a formação de estruturas e poder de mercado em mãos de uma ou mais empresas, e abusando do poder de mercado. Todavia, dispor de normas não é suficiente, indispensáveis são os órgãos supranacionais que apliquem sanções para um resultado efetivo.

O Tratado de Asunción ao criar o MERCOSUL não incorporou norma expressa de defesa da concorrência, mas a omissão supriu o Protocolo de Defesa da Concorrência ou Protocolo de Fortaleza, já recepcionado pelos ordenamentos jurídicos dos Estados-Membros. Entretanto, o momento exige mudanças, é preciso repensar estratégias para evitar condutas contrárias à concorrência, criar uma cultura de livre concorrência e prevenção que tutele a concorrência, garantir às empresas um clima de livre concorrência, possibilitar que o consumidor, como beneficiário e destinatário final, adquira produtos e serviços a preços mais baixos, de maior variedade, qualidade e inovação.

Compara-se o tratamento que a defesa da concorrência merece na União 
Européia e no MERCOSUL e conclui-se que o sistema de solução de conflitos, pela Arbitragem, não se trata da melhor opção para a aplicação das normas de defesa da concorrência no bloco.

\section{DEFESA DA CONCORRÊNCIA NA UNIÃO EUROPÉIA}

Todo sistema econômico de mercado aberto funciona bem quando nele se inserem normas de livre concorrência. Na União Européia - UE, as normas de defesa da concorrência se consolidam nos princípios do direito comunitário que permeiam todo o Tratado da União Européia -TCE. São três as principais áreas de atividade da política de livre concorrência (artigos 81 a 89 do TCE) em que a UE atua:

a) acordos e práticas contrários à concorrência;

b) setores regulados ou monopolísticos e;

c) ajudas estatais ${ }^{1}$.

Contudo, aplicar normas da concorrência não é tarefa fácil, pressupõe eliminar os obstáculos à livre circulação de mercadorias, pessoas, serviços e capitais, para garantir uma livre concorrência, oferecer segurança jurídica e estabilidade, necessárias para a expansão econômica e equilíbrio dos intercâmbios comerciais no bloco e, consolidar a integração.

O órgão que faz cumprir as normas comunitárias na UE é a Comissão, que junto às demais instituições ${ }^{2}$ e Estados-Membros trabalham aplicando a política de concorrência comunitária. $\mathrm{O}$ intuito é combater condutas que falseiam ou restringem a livre concorrência, a exemplo dos acordos "horizontais"3 entre empresas que segmentam mercados nacionais ou inter-regionais, ou das relações "verticais" entre produtores e distribuidores, dificultando o processo de integração.

${ }^{1}$ No Tratado de Lisboa, assinado em 13.12.2007, os artigos 81 a 89 receberam nova numeração (101 a 112). Entrará em vigor em janeiro de 2009, publicado no Diário Oficial da União Européia em 9 de maio de 2008.

${ }^{2}$ A colaboração da Comissão e do Conselho, na qualidade de autoridades comunitárias, proporciona o suporte necessário para cumprir com o objetivo do Tratado da UE, de criar um espaço único de livre concorrência no mercado interior (letra g) do artigo 3 do TCE.

${ }^{3}$ Acordos entre empresas que se encontram nas mesmas condições (indústrias ou prestadoras dos mesmos produtos ou serviços).

${ }^{4}$ Acordos que se situam ao longo da cadeia produtiva ou distributiva (FORGIONI, 2007, p. 23). 


\subsection{Objetivo das Normas de Concorrência}

As normas comunitárias de concorrência têm como principal objetivo criar condições necessárias para o bom funcionamento do regime de livre concorrência e livre iniciativa, inibindo formas diretas ou indiretas de discriminação ou de proteção nacional, seja de ordem legal, privada ou por parte do Estado-Membro que imponham condições aos concorrentes.

$\mathrm{Na}$ UE, aplica-se o parágrafo $1^{\underline{a}}$ do artigo 81 do $\mathrm{TCE}^{5}$, aos acordos celebrados entre empresas de Estados-Membros, que afetam os intercâmbios comerciais intracomunitários ou limitam a concorrência, porque tais condutas modificam as estruturas de concorrência, dificultando cumprir com os objetivos do mercado único, sendo um perigo à liberdade dos intercâmbios intracomunitários ${ }^{6}$. O objetivo é eliminar qualquer intervenção artificial no mercado, seja decorrente do Estado ou de âmbito privado, e o TCE proíbe no artigo $82^{7}$.

${ }^{5}$ Artigo 81 do TCE (Novo Artigo 101)

1. São incompatíveis com o mercado interno e proibidos todos os acordos entre empresas, todas as decisões de associações de empresas e práticas concertadas que sejam suscetíveis de afetar o comércio entre os Estados-Membros e que tenham por objetivo ou efeito, impedir, restringir ou falsear a concorrência no mercado interno, designadamente as que consistam em:

a) Fixar, de forma direta ou indireta, os preços de compra ou de venda, ou quaisquer outras condições de transação;

b) Limitar ou controlar a produção, a distribuição, o desenvolvimento técnico ou os investimentos;

c) Repartir os mercados ou as fontes de abastecimento;

d) Aplicar, relativamente a parceiros comerciais, condições desiguais no caso de prestações equivalentes colocando-os, por esse fato, em desvantagem na concorrência;

e) Subordinar a celebração de contratos à aceitação, por parte dos outros contraentes, de prestações suplementares que, pela sua natureza ou de acordo com os usos comerciais, não têm ligação com o objeto desses contratos.

${ }^{6}$ A jurisprudência da UE interpreta o conceito de intercâmbios intracomunitários, englobando a circulação de mercadorias, de pessoas, serviços e capitais entre os EstadosMembros. Considera afetados os intercâmbios, quando um conjunto de circunstâncias objetivas deixa entrever com um grau de probabilidade suficiente, que o acordo ou a prática abusiva limita a concorrência de forma direta ou indireta, real ou potencialmente sobre os intercâmbios econômicos entre Estados-Membros, ou dificulta cumprir com os objetivos do Tratado. 


\section{NORMAS COMUNITÁRIAS DE DEFESA DA CONCORRÊNCIA}

As normas originárias de defesa da concorrência na UE garantem um mercado aberto, e a livre concorrência é condição essencial para cumprir o objetivo de criar o mercado interno, previsto no artigo $2^{\underline{a}}$ do $\mathrm{TCE}^{8}$. A livre concorrência ocupa lugar preponderante no processo de integração, junto às liberdades de circulação de mercadorias, pessoas, serviços e capitais?

Nos artigos 81 a 89 do TCE pró́bem-se condutas contrárias à livre concorrência que a limitam ou restringem-na, por serem incompatíveis com o Mercado Comum. Veda-se a exploração abusiva de posição dominante por uma ou mais empresas e, a Comissão (órgão fiscalizador do cumprimento das normas comunitárias), por meio de suas Decisões, também auxilia no combate aos acordos e associações de empresas, porque tais acordos ou práticas colusórias limitam, impedem, restringem ou falseiam a concorrência e afetam o comércio entre os Estados-Membros.

${ }^{7}$ Artigo 82 do TCE (Novo Artigo 102)

É incompatível com o mercado interno e proibido, na medida em que tal seja susceptível de afetar o comércio entre os Estados-Membros, o fato de uma ou mais empresas explorarem de forma abusiva uma posição dominante no mercado interno ou numa parte substancial deste.

Essas práticas abusivas podem, nomeadamente, consistir em:

a) Impor, de forma direta ou indireta, preços de compra ou de venda ou outras condições de transação não equitativas;

b) Limitar a produção, a distribuição ou o desenvolvimento técnico em prejuízo dos consumidores;

c) Aplicar, relativamente a parceiros comerciais, condições desiguais no caso de prestações equivalentes colocando-os, por esse fato, em desvantagem na concorrência;

d) Subordinar a celebração de contratos à aceitação, por parte dos outros contraentes, de prestações suplementares que, pela sua natureza ou de acordo com os usos comerciais, não têm ligação com o objeto desses contratos.

${ }^{8}$ Artigo 3.

1. Para alcançar os fins enunciados no artigo 2, a ação da Comunidade implica, nos termos do disposto e segundo o calendário previsto no presente Tratado:

... g) Um regime que garanta que a concorrência não seja falseada no mercado interno; 9 Artigo $14 .$.

2. O mercado interno compreende um espaço sem fronteiras internas no qual a livre circulação das mercadorias, das pessoas, dos serviços e dos capitais é assegurada de acordo com as disposições do presente Tratado. 
A complexa tarefa de identificar condutas restritivas à concorrência foi aplainada pela jurisprudência dos Tribunais da UE (TPI e TJCE) e, das Decisões da Comissão, ao entender que tanto acordos horizontais fixando preços, repartindo mercados ou comercializando por regras preestabelecidas; como acordos verticais que proíbem exportar ou restringem a liberdade do comprador no comércio de bens, infringem "per se” o parágrafo 1, do artigo 81 do TCE. Desses acordos excluem-se apenas alguns casos pela regra de "minimis"10.

$\mathrm{Na}$ UE criou-se um regime de normas comunitárias de fiscalização, dirigidas às empresas dos Estados-Membros, proibindo adotar medidas prejudiciais à concorrência no mercado comum e nos intercâmbios intracomunitários ${ }^{11}$. O Conselho estabelece normas processuais específicas para aplicar o Tratado em matéria de concorrência, conforme o artigo 83 do $\mathrm{TCE}^{12}$ e adota Regulamentos e Diretivas que aplicam os artigos 81 e 89 do TCE.

O Conselho, ainda conta com a colaboração da Comissão e dos Tribunais TJCE e TPI para efetivar a aplicação uniforme das normas. Salienta-se que a competência e os poderes conferidos à Comissão, no artigo 85 do TCE, ${ }^{13}$ a convertem em guardiã e encarregada do controle estrito e vigilância das medidas ou práticas prejudiciais à concorrência.

${ }^{10}$ Acordos de menor importância.

${ }^{11}$ A jurisprudência da UE interpreta os intercâmbios intracomunitários com critério amplo, incluindo, não só a circulação de mercadorias, mas também de pessoas, serviços e capitais entre os Estados-Membros, porque há possibilidade de que esses intercâmbios sejam vulnerados, nos termos dos artigos 81 e 82 do TCE.

${ }^{12}$ Artigo 83.

1. Os regulamentos ou diretivas necessários à aplicação dos princípios constantes dos artigos 81 e 82 serão estabelecidos pelo Conselho, deliberando por maioria qualificada sob proposta da Comissão, após a consulta do Parlamento Europeu.

2. Os regulamentos e as diretivas referidas no número 1 têm por finalidade, designadamente:

a) Garantir o respeito das proibições referidas no número 1 do artigo 81 e no artigo 82, pela cominação de multas e adstrições.

b) Determinar as modalidades de aplicação do número 3 do artigo 81, tendo em conta a necessidade, por um lado, de garantir uma fiscalização eficaz e, por outro, de simplificar o mais possível o controle administrativo.

c) Definir, quando necessário, o âmbito de aplicação do disposto nos artigos 81 e 82, relativamente aos diversos setores econômicos.

d) Definir as funções respectivas da Comissão e do Tribunal de Justiça quanto à aplicação do disposto no presente número. 


\section{FONTES DO DIREITO DA CONCORRÊNCIA NA UNIÃO EUROPÉIA} fontes:

O direito da concorrência na UE auxilia-se fundamentalmente das seguintes

a) Tratado (TCE) que originou a UE, no vértice da hierarquia do ordenamento jurídico comunitário. Constitui o direito originário ${ }^{14}$ (artigos 81 a 89 sobre defesa da concorrência);

b) Regulamentos do Conselho ${ }^{15}$ e da Comissão (sobre concentração de empresas de dimensão comunitária, categorias de acordos e outros). Constituem o direito derivado ${ }^{16}$;

c) Decisões da Comissão (dirigidas individualmente a empresas ou instituições da UE, sobre práticas de acordos, etc), também constituem direito derivado;

d) Jurisprudência do Tribunal de Justiça das Comunidades Européias TJCE, do Tribunal de Primeira Instância - TPI e dos tribunais nacionais dos Estados-Membros;

e) Prática administrativa da Comissão ${ }^{17}$ e dos órgãos nacionais de defesa da concorrência;

f) Princípios do direito comunitário (primazia, efeito direto, subsidiariedade);

g) Doutrina especializada.

e) Definir as relações entre as legislações nacionais e as disposições constantes da presente seção ou as adotadas em execução do presente artigo.

13 Artigo 85.

1. Sem prejuízo do disposto no artigo 84 , a Comissão zela pela aplicação dos princípios enunciados nos artigos 81 e 82, e a pedido de um Estado-Membro ou oficiosamente e em cooperação com as autoridades competentes dos Estados-Membros, que lhe prestarão assistência, a Comissão instruirá os casos de presumível infração a tais princípios. Se a Comissão verificar que houve infração, proporá os meios adequados para se lhe pôr termo.

2. Se a infração não tiver cessado, a Comissão declarará essa infração aos princípios, em decisão devidamente fundamentada. A Comissão pode publicar a sua decisão e autorizar os Estados-Membros a tomarem as medidas, de que fixar as condições e modalidades, necessárias para sanar a situação.

${ }^{14}$ Normas inseridas nos Tratados que fundaram a União Européia.

${ }^{15}$ Regulamentos relativos à aplicação das normas de livre concorrência na União Européia.

${ }^{16}$ Normas derivadas das instituições comunitárias: Regulamentos, Diretivas, Decisões e outros atos.

${ }^{17}$ A Comissão elabora Decisões, e Comunicações gerais sobre assuntos específicos, e mesmo sem caráter obrigatório servem de suporte nos relatórios anuais sobre a evolução da política de concorrência. 
Além das fontes mencionadas, as autoridades de órgãos administrativos, tribunais de defesa da concorrência e órgãos jurisdicionais obtêm informações necessárias da Comissão, e no âmbito processual, os órgãos jurisdicionais nacionais dos Estados-Membros contam com o Procedimento Prejudicial, previsto no artigo 234 do $\mathrm{TCE}^{18}$, que permite ao juiz nacional submeter o caso perante o Tribunal de Justiça das Comunidades Européias-TJCE, que decidirá o acórdão interpretativo e vinculante para ambas as partes.

O juiz nacional dispõe do procedimento, previamente tramitado na Comissão, que lhe permite avaliar a posição da Comissão no mesmo assunto ${ }^{19}$, podendo o juiz confirmar a opinião da Comissão ou expor a questão ao TJCE para sua interpretação, em caráter prejudicial e, não havendo dúvidas quanto à aplicabilidade ou inaplicabilidade das disposições comunitárias ${ }^{20}$, o juiz nacional deve dar andamento ao processo e decidir sem interrupção.

A Comissão e o TJCE elaboraram, também, orientações gerais destinadas a facilitar a tarefa dos tribunais, mas não interferem na independência dos órgãos jurisdicionais nacionais.

${ }^{18}$ Artigo 267 do TCE

O Tribunal de Justiça é competente para decidir a título prejudicial sobre:

a) a interpretação do presente Tratado;

b) a validade e interpretação dos atos adotados pelas Instituições da Comunidade e pelo BCE;

c) a interpretação dos estatutos dos organismos criados por ato do Conselho, desde que esses estatutos o prevejam.

Sempre que uma questão desta natureza seja suscitada perante qualquer órgão jurisdicional de um dos Estados-Membros, esse órgão pode, se considerar que uma decisão sobre essa questão é necessária ao julgamento da causa, pedir ao Tribunal de Justiça que sobre ela se pronuncie.

Sempre que uma questão desta natureza seja suscitada em processo pendente perante um órgão jurisdicional nacional, cujas decisões não sejam susceptíveis de recurso judicial previsto no direito interno, esse órgão é obrigado a submeter a questão ao Tribunal de Justiça.

${ }^{19}$ As autoridades comunitárias informam a situação do procedimento tramitado na Comissão, e a conveniência de suspender o procedimento nos litígios que instrui. As informações revelam as circunstâncias econômicas e jurídicas que conduziram o acordo ou a prática, objeto da denúncia desde seu nascedouro. Tais circunstâncias podem ser determinantes para resolver o litígio. A informação garante ao juiz nacional que sua resolução não será contrária a uma Decisão da Comissão já adotada ou por adotar, e o incitará a prosseguir com o procedimento.

${ }^{20}$ A esse respeito ver o Acórdão TJCE, Delimitis/Henninger Bräu. Assunto C-234/89, Rec. 1991, p. I-935-983, parágrafo 50. 


\section{NORMAS APLICÁVEIS ÀS EMPRESAS}

A proibição nos artigos 81 e 82 do TCE têm como destino todas as empresas: grandes, médias e pequenas, privadas e públicas, nacionais e estrangeiras, associações de empresas com atividades próprias ou de empresas associadas, que tenham por objetivo impedir, limitar ou falsear o jogo da concorrência ou utilizar sua posição dominante para restringir a concorrência na Comunidade. O conceito de empresa é amplo e funcional, representa um conjunto uniforme, destinado a um objeto de direito determinado, com fatores pessoais, materiais e imateriais, que se destinam a alcançar um fim econômico determinado, inclusive empresas vinculadas aos organismos públicos.

A jurisprudência da UE tem decidido pelo caráter funcional e genérico da empresa, ao considerar empresa, toda pessoa física ou jurídica, entidade de direito público, monopólios comerciais e financeiros, mesmo quando integrados a um ministério ${ }^{21}$. Ainda que sejam empresas formadas por contrato público, empresas estatais de patrimônio público, em regime especial, de gestão econômica e contábil própria, operadores de instalações públicas de telecomunicação, organizações de comércio exterior dos estados socialistas ${ }^{22}$, ou entes subordinados aos municípios, regiões, estados e comunidades de estados e tenham ânimo de lucro, todos esses são considerados como empresas.

O critério comum para aplicar as normas de defesa da concorrência é delimitar o âmbito de aplicação do direito comunitário, respeitando o ordenamento jurídico nacional, porque os acordos ${ }^{23}$ e o abuso de posição dominante ${ }^{24}$ que afetam o comércio os Estados-Membros são proibidos pelo Tratado.

${ }^{21}$ Acórdão TJCE-Comisión/Italia (monopólio dos produtos de tabaco). Assunto 118/ 85, Rec. 1987, pp. 2599 a 2620.

${ }^{22}$ Decisão da Comissão sobre Importações de alumínio da Europa Oriental. DO 1985 $\mathrm{n}^{\mathrm{a}} \mathrm{L}$ 92, pp 1 a 37.

${ }^{23}$ O parágrafo 1 do artigo 81 do TCE proíbe acordos restritivos da concorrência subscritos entre empresas estabelecidas em diferentes Estados-Membros, que dificultem os intercâmbios intra-comunitários. A proibição abrange os acordos em que participam empresas de um Estado-Membro e efetuam importações procedentes de outros EstadosMembros ou exportam a estes.

${ }^{24} \mathrm{O}$ artigo 82 do TCE proíbe práticas abusivas de empresa dominante no mercado, com sede em terceiro país. Tais práticas estão sujeitas ao direito comunitário, quando o abuso modifica as estruturas da concorrência, além dos limites deste Estado. 
As condutas contra a livre concorrência, praticadas por empresas da UE, recaem sobre acordos e práticas abusivas que restringem a liberdade dos intercâmbios intracomunitários ou ameaçam o comércio comunitário, dificultando cumprir com os objetivos do mercado único ${ }^{25}$.

A forma jurídica da empresa, de direito público ou privado, lugar de estabelecimento, âmbito de atividade ou relações de propriedade são pouco importantes para a defesa da concorrência. Toda pessoa fisica ou jurídica, coletividade na função de provedor ou comprador de mercadorias, prestações industriais e comerciais que desenvolva uma atividade econômica autônoma está inserida.

\section{APLICAÇÃO DO DIREITO DA CONCORRÊNCIA NA UNIÃO EUROPÉIA}

O órgão encarregado de aplicar a livre concorrência é a Comissão Européia, por meio da Direção Geral da Concorrência. A Comissão, além de ter o privilégio da iniciativa legislativa em geral, possui extensos poderes em matéria de concorrência para propor ações judiciais, investigar, decidir, sancionar e aplicar os artigos 81 a 89 do TCE, Regulamentos e Decisões da UE. Não obstante, os amplos poderes conferidos à Comissão, esta não tem competência jurisdicional, porque somente exerce um poder discricionário.

A competência do controle judicial foi outorgada ao juiz comunitário e o Tratado atribuiu a competência jurisdicional plena ao Tribunal de Primeira Instância e ao Tribunal de Justiça da UE e são os juízes que interpretam o Tratado $^{26}$, Regulamentos e Decisões da Comissão e aplicam as sanções previstas nas normas do direito comunitário da concorrência.

\section{PROCEDIMENTO ADMINISTRATIVO: TRAMITAÇÃO DA DENÚNCIA}

Recebido o requerimento de comprovação ou suspensão, a Comissão examina os aspectos de fato e de direito apresentados pelo denunciante. Constata se esses aspectos revelam uma prática contra a concorrência no mercado comum ou afetam o comércio de Estados-Membros ${ }^{27}$.

${ }^{25}$ Os artigos 81 e 82 do TCE se aplicam aos acordos entre empresas de terceiros países cuja finalidade é impedir, limitar ou falsear a concorrência no Mercado Comum, ou afetam os intercâmbios econômicos intracomunitários e, quando alteram a concorrência em mais de um Estado-Membro.

${ }^{26}$ Artigo 229 do TCE.

No que diz respeito às sanções neles previstas, os regulamentos adotados em conjunto pelo Parlamento Europeu e pelo Conselho, por força das disposições do presente Tratado, podem atribuir plena jurisdição ao Tribunal de Justiça. 
As garantias processuais concedidas ao denunciante têm três fases sucessivas:

a) a primeira começa com a apresentação da denúncia. A Comissão transmite a denuncia à parte contrária e solicita informações. Em função dos resultados das investigações, a Comissão decide se procede ou não ao exame detalhado dos fatos para iniciar o procedimento formal. Caso a resposta a essa questão seja negativa, será dada por terminada a primeira fase informal do procedimento;

b) a segunda fase inicia-se com a comunicação em que a Comissão expõe ao denunciante os motivos pelos quais não lhe parece justificado aceitar sua demanda e lhe permite manifestar-se por escrito, no prazo por ela fixado;

c) na terceira fase, a Comissão toma conhecimento das observações do denunciante, examina se é objeto de revisão da posição adotada. Não sendo caso de revisão, indefere a denúncia mediante decisão.

\subsection{Procedimento Administrativo da Comissão}

Uma vez aceito o procedimento formal da denúncia, passa por cinco fases: instrução, comunicação de infrações, audiência dos interessados, emissão da opinião do Comitê Consultivo da concorrência e, decisão da Comissão que será recorrível ao Tribunal de Justiça.

$\mathrm{Na}$ qualidade de responsável do procedimento, a Comissão deve:

a) ouvir as empresas e associações de empresas afetadas, demandantes e terceiros interessados;

b) proteger da divulgação os segredos de negócios das empresas e outras comunicações confidenciais;

c) consultar às autoridades competentes de concorrência nos EstadosMembros; e

d) zelar pela publicação das decisões adotadas.

Em matéria de informação e verificação, se os dados reunidos pela Comissão não são suficientes para esclarecer os fatos, poderá a Comissão, inclusive, impor as sanções previstas nos artigos 85 e 284 do $\mathrm{TCE}^{28}$.

${ }^{27}$ Comissão ao considerar que as circunstâncias que examina não lhe permitem dar parecer favorável ao pedido de comprovação e suspensão, por infração aos artigos 81 ou 82 , comunicará os motivos ao denunciante e fixa prazo para enviar por escrito suas possíveis observações.

${ }^{28}$ Artigo 284 do TCE.

Para o desempenho das funções que lhe são confiadas, a Comissão pode recolher todas as informações e proceder a todas as verificações necessárias, dentro dos limites e condições fixadas pelo Conselho, nos termos do presente Tratado. 


\section{COLABORAÇÃO DA COMISSÃO COM OS ÓRGÃOS DE CONCORRÊNCIA DOS ESTADOS-MEMBROS}

A Comissão, como autoridade comunitária da política da concorrência, colabora com as autoridades nacionais, responsáveis da concorrência e, com os órgãos jurisdicionais ordinários dos Estados-Membros. É freqüente que, a requerimento dos órgãos jurisdicionais dos Estados-Membros, a Comissão apóie com os meios que dispõe, remetendo informações escritas ou pelos funcionários da Comissão que fazem declarações perante o juiz nacional ${ }^{29}$.

As informações que a Comissão fornece são de quatro categorias:

a) de caráter processual, sobre a situação do procedimento tramitado, perante a Comissão e a data provável da conclusão;

b) de caráter jurídico, sobre a jurisprudência do TJCE ou prática administrativa da Comissão $0^{30}$;

c) de caráter provisional sobre as possibilidades de isenção de um acordo, num litígio que o juiz instrui ${ }^{31}$;

d) de caráter econômico, detalhando a fonte respectiva.

A colaboração entre a Comissão e os órgãos jurisdicionais dos EstadosMembros, no processo em andamento perante o juiz nacional, rege-se pelos princípios da objetividade e a neutralidade, uma vez fornecidas tais informações, a Comissão se abstém de influenciar na decisão do juiz nacional, não mantendo mais contato com ele, nem com as partes.

Caso o requerimento das partes não estiver legitimado, pela formalidade do respectivo mandado do juiz nacional, a colaboração da Comissão com os órgãos jurisdicionais dos Estados-Membros escapa de sua competência e, não serão fornecidas as informações necessárias ao juiz nacional, mesmo que a sua resposta favoreça o andamento do processo. Já que o processo, estando sub judice, é de competência exclusiva dos órgãos jurisdicionais nacionais, assim como a garantia da audiência, dos direitos de defesa e da sentença.

${ }^{29}$ Por requerimento escrito emanado de órgão jurisdicional nacional para informações desejadas, a Comissão intervém na qualidade de amicus curiae, para dar andamento ao pedido.

${ }^{30}$ Além das decisões formais, incluem-se também as cartas administrativas e outras formas de procedimento e, os Regulamentos de isenção por categoria que a Comissão adota.

${ }^{31}$ Ajudam ao juiz nacional a pronunciar-se sobre prorrogação ou continuação de seu procedimento e contribuem para prevenir retardamentos inúteis na administração de Justiça. 


\section{CONTROLE JUDICIAL}

O TJCE exerce o controle judicial sobre a atividade das instituições da comunidade $^{32}$, no tocante à matéria ou aos procedimentos adotados pela Comissão ao aplicar os artigos 81 e 82 do TCE. Esses atos podem ser impugnados pelo Conselho e os Estados-Membros, interpondo um recurso de nulidade ao TJCE, por carecer de competência, vícios substanciais de forma ou violação ao Tratado ou a qualquer norma jurídica relativa ou desvio de poder.

As pessoas físicas e jurídicas podem interpor recurso contra as Decisões da Comissão, das quais são destinatárias ou contra aquelas que, mesmo na forma de um regulamento ou de uma decisão dirigida a outra pessoa, as afeta direta e individualmente ${ }^{33}$. Os recursos são interpostos ao TPI, com competência para conhecê-los e da decisão do TPI cabe recurso perante o TJCE, que se pronunciará exclusivamente sobre questões de direito.

Os recursos interpostos ao TPI e ao TJCE não têm efeito suspensivo e, esses órgãos podem ordenar a suspensão da execução do ato impugnado com base no artigo 242 do $\mathrm{TCE}^{34}$, se as circunstâncias assim o exigirem. Com base no artigo 243 do $\mathrm{TCE}^{35}$ podem ordenar medidas provisórias necessárias nas causas que estejam conhecendo. Não obstante, pedidos de adiamento da execução das Decisões da Comissão constituem prática habitual.

Pelo princípio do controle da legalidade, quando o recurso tem fundamento, os órgãos jurisdicionais da UE se limitam a declarar nulo o ato

32 Artigo 230 do TCE.

O Tribunal de Justiça fiscaliza a legalidade dos atos adotados em conjunto pelo Parlamento Europeu e pelo Conselho, dos atos do Conselho, da Comissão e do BCE, que não sejam recomendações ou pareceres, e dos atos do Parlamento Europeu destinados a produzir efeitos jurídicos em relação a terceiros.

${ }^{33}$ Las empresas afectadas en un procedimiento administrativo ante la Comisión pueden recurrir las decisiones de esta Institución cuando haya declarado que una concentración es incompatible con el mercado común. (BRIONES et al., 1999, p. 353).

${ }^{34}$ Artigo 242.

Os recursos perante o Tribunal de Justiça não têm efeito suspensivo. Mas o Tribunal de Justiça pode ordenar a suspensão da execução do ato impugnado, se considerar que as circunstâncias o exigem.

${ }^{35}$ Artigo 243.

O Tribunal de Justiça, nas causas submetidas à sua apreciação, pode ordenar as medidas provisórias necessárias. 
impugnado, ou declarar a omissão contrária ao Tratado e, objeto do recurso. Compete à instituição comunitária interessada adotar as medidas necessárias para a execução do acórdão ${ }^{36}$.

O TJCE pronuncia-se nos recursos por omissão ${ }^{37}$ que infringem o Tratado e são interpostos contra uma instituição da Comunidade que omitiu pronunciar-se. Ainda, as pessoas físicas ou jurídicas podem interpor recurso de omissão, se a Comissão omitiu dirigir-lhes um ato jurídico ou procedimento.

\section{INTEGRAÇÃO DO MERCOSUL}

Das muitas tentativas de integração que ocorreram no século XX, a UE e o MERCOSUL constituem os processos de integração econômica regional com maiores pretensões ${ }^{38}$, porque outros blocos econômicos alcançaram fases de integração menos ambiciosas, como os acordos de preferências, união aduaneira ou uma zona de livre comércio. O bloco formado por Argentina, Brasil, Paraguai, Uruguai, e a Venezuela, a caminho de se incorporar, pretende chegar a um mercado comum, mas não possui a estrutura orgânica mínima que faça avançar o processo de integração de uma forma mais efetiva.

${ }^{36}$ Artigo 233 do TCE.

A Instituição ou as Instituições de que emane o ato anulado, ou cuja abstenção tenha sido declarada contrária ao presente Tratado, devem tomar as medidas necessárias à execução do acórdão do Tribunal de Justiça.

Essa obrigação não prejudica aquela que decorre da aplicação do segundo parágrafo do artigo 288.

O presente artigo se aplicará igualmente ao $B C E$.

${ }^{37}$ Recurso por omissão só é admissível quando a instituição, objeto do recurso, foi requerida previamente para atuar. $\mathrm{O}$ procedimento exige que tendo transcorrido o prazo de dois meses a partir do requerimento e, não havendo uma posição, o recurso pode ser interposto dentro de um novo prazo de dois meses.

Artigo 232 do TCE.

Se, em violação do presente Tratado, o Parlamento Europeu, o Conselho ou a Comissão se abstiverem de pronunciar-se, os Estados-Membros e as outras instituições da Comunidade podem recorrer ao Tribunal de Justiça para que declare verificada essa violação.

${ }^{38}$ A aparente semelhança da UE e MERCOSUL foi objeto de análise anterior da autora: "O MERCOSUL não tem órgãos supranacionais como ocorre com a União Européia, 
A falta de coesão entre os Estados-Membros do MERCOSUL impede também vislumbrar que o pilar fundamental para o desenvolvimento é o acesso à livre concorrência. A experiência européia é válida, primeiro porque, na UE, a forma de aplicação das normas de defesa da concorrência serve de parâmetro para o tratamento que as mesmas merecem no âmbito do MERCOSUL, salvadas as diferenças ${ }^{39}$ e, segundo, porque serve de reflexão para analisar a efetividade do sistema do MERCOSUL, não só em matéria de concorrência, como em todas as demais áreas do direito.

Necessário ainda, diferenciar as peculiaridades de ambos os blocos, que per se explicam a parcimônia na integração do Cone Sul. A integração na Europa ocorre no pós-guerra, para reestruturar a sua economia que ficou assolada pelos conflitos bélicos, e o caminho de recuperação passou por um profundo processo de integração. A UE, hoje com 27 Estados-Membros, contrasta com o MERCOSUL, criado pelo jovem Tratado de Assunção-TA em 1991, também com o objetivo de alcançar um mercado comum, mas esbarra em barreiras técnicas e divergências políticas. Amarga-se a falta de uma estrutura orgânica, capaz de gerir a complexidade das prioridades dos Estados-Membros.

mas isso não implica que futuramente não possa tornar-se um mercado comum ou uma união política e econômica. Para isso, será necessário que as constituições, dos Estados partes, sejam modificadas, permitindo delegar poderes aos órgãos do MERCOSUL. Contudo, não se pode deixar de destacar a fidelidade do MERCOSUL ao modelo clássico de intergovernabilidade ou de cooperação, que caracteriza o mecanismo de decisões, de grande parte das organizações internacionais”. (PRADO ENRÍQUEZ, 1995, p. 731-740).

${ }^{39}$ Araceli Mangas refere com muita proriedade: "La UE y MERCOSUR comparten parcialmente algunos objetivos económicos, pero no se dotan de los mismos medios jurídicos e institucionales. Los dos OIs pretenden en sus Tratados constitutivos lograr entre sus Estados miembros la libre circulación de mercancías, es decir una zona de libre comercio, y seguir avanzando hacia la unión aduanera fijando un arancel exterior común y una política comercial común. Y una tercera meta consistiría en lograr un mercado común en el que los factores de producción puedan circular libremente (personas y servicios) y las condiciones de competencia, normas de armonización, etc., estén coordinadas. Pero los sistemas institucionales son muy distintos formal y materialmente. Los mimetismos retóricos producen falsas apariencias. Es muy difícil comparar, casi imposible, el MERCOSUR con las Comunidades Europeas. No hay términos posibles de comparación institucional dada la insalvable distancia entre la simpleza o el «vacío» institucional del MERCOSUR y la «tela de araña» del sistema institucional europeo". (MANGAS MARTIN, 1997, p. 9-10). 
$\mathrm{Na}$ UE, as normas de concorrência estão inseridas nos objetivos gerais e garantidas pelo eficiente sistema econômico que sustenta o bloco, no MERCOSUL é comum a prática de condutas, como acordos que repartem geograficamente mercados nacionais e restringem a concorrência e, afetam o funcionamento do mercado comum. Essas condutas dificultam a aplicação de normas de concorrência, é a chamada "cláusula de afetação do mercado comum”. Se continuar assim, de nada servirá suprimir barreiras, como direitos de aduana ao trânsito de mercadorias entre Estados-Membros, se as empresas, mediante acordos, levantam barreiras equivalentes e dividem mercados (FERNADEZ DE LA GANDARA; CALVO CARAVACA, 2005, p. 274).

Mostra-se neste estudo a necessidade dos Estados-Membros envidar esforços para alcançar os objetivos propostos para o MERCOSUL, criando instituição e/ou desdobramento de uma ou mais instituições encarregadas de fazer cumprir normas de defesa da concorrência, a semelhança dos órgãos da Comissão, do TPI e do TJCE na UE. Não se trata de copiar o modelo da UE, mas aprofundar um sistema de integração que se adapte à realidade dos Estados-Membros do Cone Sul. Nesse sentido, Guido Soares ${ }^{40}$ afirma que a experiência européia é de utilidade pelos resultados alcançados no bloco.

\section{DEFESA DA CONCORRÊNCIA NO MERCOSUL}

Embora inexista norma expressa sobre defesa da livre concorrência no TA, o penúltimo parágrafo do artigo $1^{\underline{a}}$ prevê "assegurar condições adequadas de concorrência entre os Estados-Partes” ${ }^{41}$. E, mesmo de forma indireta, a livre concorrência está inserida nos objetivos gerais do MERCOSUL, junto à livre

40 "As comparações do Mercosul com a Comunidade Européia são de toda utilidade, visto que esta experiência européia representa a mais perfeita realização, na atualidade, de um sistema normativo regional de integração econômica, que tem produzido resultados palpáveis e que tem cumprido com suas finalidades maiores". (SOARES, 1998, p. 68).

${ }^{41}$ Artigo 1a. Os Estados-Partes decidem constituir um Mercado Comum, que deverá estar estabelecido a 31 de dezembro de 1994, e que se denominará Mercado Comum do Sul (MERCOSUL).

Este Mercado Comum implica:

A livre circulação de bens, serviços e fatores produtivos entre os países, por meio, entre outros, da eliminação dos direitos alfandegários, restrições não-tarifárias à circulação de mercadorias ou de qualquer outra medida de efeito equivalente; $\mathrm{O}$ estabelecimento de uma tarifa externa comum e a adoção de uma política comercial 
circulação de bens, serviços e fatores produtivos entre Estados-Membros. Fortalecer o mercado comum dependerá do agir responsável de governos dos Estados-Membros para harmonizar as legislações sobre concorrência e, possibilitar que o processo de integração seja mais efetivo.

Outra menção indireta sobre defesa da concorrência, ocorre no artigo $4^{\underline{a}}$ do TA que confirma o compromisso dos Estados-Membros de coordenar as respectivas políticas nacionais, a fim de elaborar normas comuns sobre a concorrência comercial ${ }^{42}$. Porém, o problema a resolver é a inexistência de um mecanismo que possibilite aplicar de forma direta as normas emanadas dos órgãos institucionais do MERCOSUL. Os ordenamentos jurídicos nacionais não possibilitam exigir que os Estados-Membros cumpram normas elaboradas por órgãos da administração do MERCOSUL, não sendo de órgãos supranacionais que editem normas obrigatórias ${ }^{43}$ de cumprimento imediato nos Estados-Membros. É preciso que sejam recepcionadas na legislação interna (nacional), de conformidade com cada ordenamento jurídico, o que além de dificultar a efetiva defesa da concorrência, retarda a integração.

Contrariamente, na UE os Tratados e Regulamentos são de aplicação direta e imediata e, as Diretivas servem como instrumentos de harmonização, que

comum em relação a terceiros Estados ou agrupamentos de Estados e a coordenação de posições em foros econômico-comerciais regionais e internacionais; A coordenação de políticas macroeconômicas e setoriais entre os Estados-Partes de comércio exterior, agrícola, industrial, fiscal, monetária, cambial e de capitais, de serviços, alfandegária, de transportes e comunicações e outras que se acordem -, a fim de assegurar condições adequadas de concorrência entre os Estados-Partes; e o compromisso dos EstadosPartes de harmonizar suas legislações, nas áreas pertinentes, para lograr o fortalecimento do processo de integração.

${ }^{42}$ Artigo 4. Nas relações com terceiros países, os Estados-Partes assegurarão condições eqüitativas de comércio. Para tal fim, aplicarão suas legislações nacionais, para incluir importações cujos preços estejam influenciados por subsídios, dumping ou qualquer outra prática desleal. Paralelamente, os Estados-Partes coordenarão suas respectivas políticas nacionais com o objetivo de elaborar normas comuns sobre concorrência comercial.

${ }^{43}$ Quanto à obrigatoriedade e executoriedade da lei, Maria Helena Diniz escreve: “ Terse-á a existência jurídica da lei se esta for emanada por poder competente e se preenchidas as formalidades necessárias. A executoriedade da lei dependerá da ordem dada pelo Executivo para que se observe e faça observar o preceito legal. A promulgação, por ser ato de competência do Executivo, é que dará força executória à lei, que tenha sancionado, dando-lhe autenticidade [...].” (DINIZ, 1999, p. 46). 
os Estados-Membros cumprem obrigatoriamente, sob pena de serem responsabilizados patrimonialmente pelo inadimplimento na regulamentação.

No MERCOSUL, a omissão de inserir normas de defesa da concorrência no TA foi suprida na Decisão 21/94 do Conselho do Mercado Comum CMC, que mais tarde originou o Protocolo de Defesa da Concorrência ou Protocolo de Fortaleza - PF, que os Estados-Membros assinaram, em 17.12.1996, para harmonizar a defesa da concorrência no bloco.

Entende-se que o sucesso da aplicação das normas desse protocolo dependerá de sua instrumentalização, na busca de um crescimento equilibrado e harmonioso das relações intra-bloco. O PF incentiva a competitividade das empresas no MERCOSUL, e assegura livre aceso ao mercado, de empresas nacionais e de outros espaços econômicos.

O sistema adotado no TA, protocolos, decisões e diretrizes é de caráter intergoverna-mental e, na ausência de um órgão jurisdi-cional, os conflitos decorrentes das relações comerciais são resolvidos pelos mecanismos próprios de organismos clássicos de direito internacional público. De maneira que, o MERCOSUL por mais boa vontade em aplicar as normas de defesa da concorrência, encontra barreiras para exigir a obrigatoriedade e executoriedade das mesmas. Entretanto, paradoxalmente, a definição das normas de defesa da concorrência e das práticas restritivas, enunciadas no artigo $4^{\underline{a}}$ do $\mathrm{PF}$, apresenta semelhanças com a definição adotada no direito comunitário europeu.

Ocorre, porém, que na UE existem órgãos judiciários supranacionais que impõem o cumprimento das normas e aplicam multas pelo inadimplemento, já no MERCOSUL inexistem órgãos judiciários acima da competência dos Estados-Membros. Agrava-se, também, por traços culturais comuns que não se caracterizam, propriamente, por cumprir acordos se não sofrerem uma sanção imposta por um órgão judiciário. Daí a necessidade de criar órgãos com poderes supranacionais para impor, coativamente, as normas no MERCOSUL. Do contrário, os problemas continuarão sem solução satisfatória para as partes envolvidas.

Entende-se válida a experiência do direito comunitário europeu, porque criou tribunais supranacionais para solucionar os conflitos entre os EstadosMembros e entre seus cidadãos. Neste ponto, destaca o papel decisivo dos tribunais TJCE e TPI ao dirimir conflitos, desenvolvendo critérios claros e precisos sobre a aplicação das normas comunitárias de defesa da concorrência na UE.

A ausência de órgãos supranacionais no MERCOSUL atrasará muito o processo de integração ${ }^{44}$. Entende-se que o modelo de controle da aplicação 
de normas de concorrência, confiado ao Comitê de Defesa da Concorrência (órgão de natureza governamental, integrado pelos órgãos nacionais de defesa da concorrência de cada Estado-Membro), trata-se de um órgão de cooperação que toma decisões consensuais e por unanimidade, e que dificulta a aplicação de normas concorrenciais. Não se reestruturando o MERCOSUL para dotálo de órgãos e instrumentos necessários e ágeis, que apliquem de forma efetiva as normas e, que os Estados-Membros cumpram obrigatoriamente, toda boa vontade dos governos para o avanço na integração será inútil.

\section{CONCLUSÃO}

A ordem mundial exige abertura de mercados para fortalecer as economias nacionais e regionais. E no compasso da cada vez crescente globalização da economia, a maneira de garantir um sistema econômico eficiente inicia-se buscando critérios que controlem as operações de concentração de empresas, para evitar estruturas de mercado ou abuso de poder de mercado, nas mãos de uma ou mais empresas que prejudicam a livre concorrência. E os processos de integração também se vêm obrigados a legitimar políticas públicas e normas de defesa da concorrência, que garantam eficiência ao sistema econômico, como um meio de consolidar a integração.

A política de livre concorrência da União Européia não teria sido possível se os Estados-Membros mantivessem barreiras para a livre concorrência, circulação de bens, serviços e capitais no mercado interno. Nesse aspecto, constituiu de grande valia a dotação de órgãos supranacionais, como o Conselho, Comissão, Parlamento, Tribunal de Justiça, Tribunal de Primeira Instância e Tribunal de Contas que, no âmbito de suas competências, contribuem na aplicação das normas da concorrência para alcançar o mercado comum.

No MERCOSUL, há necessidade de criar órgãos supranacionais não só para aplicar o Protocolo de Fortaleza, mas todas as normas, não sendo suficiente o "compromisso" de constituir um mercado comum. A solução

${ }^{44}$ Heber Arbuet, já entendia "[...] Una vez que el Mercosur se haya establecido definitivamente, necessitará de este tipo de instituciones supranacionales y de otras propias del Derecho Comunitario. Entendemos que esto resulta imprescindible para impulsar su desarrollo y solucionar no sólo los problemas que surjan entre Estados, sino también aquellos que se produzcan entre estos y particulares y entre privados entre sí, proporcionando mecanismos que atiendan al interés comunitario sin ofender la sensibilidad nacional ni afectar la soberanía, pero que se impongan rápidamente a las voluntades particulares.” (ARBUET VIGNALI, 1996, p. 39-40). 
dos conflitos por um tribunal supranacional vai além do mecanismo de solução de controvérsias da arbitragem, instituído no Protocolo de Olivos. Deve ser criado um sistema normativo capaz de alcançar, plenamente, a livre concorrência, circulação de bens e serviços, de capitais e investimentos, de pessoas e, a liberdade de estabelecimento no mercado regional. Do contrário, pouco ou nada servirão as tentativas de harmonizar normas de concorrência nos Estados-Membros, as empresas continuarão celebrando acordos e levantando barreiras que afetam o funcionamento do mercado comum, impedindo o direito de escolha do consumidor, destruído pela ação nociva de monopólios, oligopólios e outras condutas anticoncorrenciais.

Embora o Protocolo de Fortaleza represente um começo para a livre concorrência no MERCOSUL, há necessidade de harmonizar políticas macroeconômicas e aprofundar o modelo de integração regional, não só criando um sistema eficaz de defesa da concorrência que reprima o abuso de poder no mercado, e que os agentes econômicos atuem com liberdade no mer-cado interno, mas também por exigências do próprio mercado globalizado, sob pena de comprometer irremediavelmente o MERCOSUL.

O futuro cobrará dos governos dos Estados-Membros do MERCOSUL a histórica tarefa entregue nas mãos destes. Devemos encontrar o caminho para uma maior integração institucional, dotar o bloco de legislação e órgãos que combatam e punam toda iniciativa privada ou pública, que iniba ou retarde a abertura dos mercados ou pratique condutas contrárias à livre concorrência. Somente ocorrendo mudanças econômicas, culturais e sociais o mercado interno do bloco será dinamizado, possibilitando vida mais digna aos cidadãos.

\section{REFERÊNCIAS}

ACORDO de cooperação entre Brasil e Argentina, relativo à cooperação entre autoridades de defesa da concorrência para aplicação das leis de concorrência, de 16 de outubro de 2003. Disponível em: <http://www.seae.fazenda.gov.br/ central_documentos/legislacao〉. Acesso em: 5 set. 2007.

ACORDO sobre o Regulamento do Protocolo de Defesa da Concorrência do MERCOSUL, de 5 de dezembro de 2002. Disponível em: <http:// www.sice.oas.org/trade/MRCSR/agcompop.asp>. Acesso em: 10 ago. 2007.

ARBUET VIGNALI, Heber. El Protocolo de Ouro Preto: una excusa para hablar de integración. In: MERCOSUR: balance y perspectivas. Montevideo: Fundación de cultura universitaria, 1996. p. 39-40. 
ARGENTINA. Ley 25.156. Sancionada el 25 de agosto de 1999 y promulgada el 16 de septiembre de 1999. Ley de defensa de la competencia. Disponível em: <http://www1.hcdn.gov.ar/dependencias/cdconsumidor/leyes/ ley25156.htm>. Acesso em: 10 out. 2007.

BRASIL. Lei n. 8.884, de 11 de junho 1994. Transforma o Conselho Administrativo de Defesa Econômica (Cade) em Autarquia, dispõe sobre a prevenção e a repressão às infrações contra a ordem econômica e dá outras providências. Disponível em: <http://www.seae.fazenda.gov.br/central_documentos/ legislacao/3-5-1-defesa-da-concorrencia/LEI-8884>. Acesso em: 18 nov. 2007.

BRIONES, Juan et al. El control de las concentraciones en la Unión Europea. Madrid: Marcial Pons, 1999.

DINIZ, Maria Helena. Lei de introdução ao Código Civil interpretada. 5. ed. São Paulo: Saraiva, 1999.

EUROPEAN COURT OF JUSTICE. Case 234/89, 28th February, 1991. Stergios Delimitis v. Henninger Brau. European Court reports 1991 Page I00935.

FERNANDEZ DE LA GANDARA, Luis; CALVO CARAVACA, Alfonso-Luis. Derecho Mercantil Internacional. 4. ed. Madrid: Editorial Tecnos, 2005.

FORGIONI, Paula Andrea. Direito concorrencial e restrições verticais. São Paulo: Ed. Revista dos Tribunais, 2007.

MANGAS MARTIN, Araceli. Unión Europea y Mercosur: marco institucional y jurídico. Rivista di Diritto dell'integrazione e unificazione del Diritto in Europa e in Americalatina, Roma, n. 4, p. 9-30, 1997.

MERCOSUL/CMC/DEC. № 15/06. Entendimento sobre cooperação entre as autoridades de defesa de concorrência dos estados partes do MERCOSUL para o controle de concentrações econômicas de âmbito regional. Disponível em: $<$ http://www.mercosur.int/msweb/portal\%20intermediario/Normas/normas_web/ Decisiones/PT/DEC_015-006_PT_EntendCoopAutoDefConc.pdf>. Acesso em: 22 set. 2007.

PORTUGAL. Ministério dos Negócios Estrangeiros. Versões consolidadas do Tratado da União Européia e do Tratado sobre o funcionamento da União Européia como alterados pelo Tratado de Lisboa. Lisboa, fev. 2008. Disponível em: <http://www.eu2007.pt/NR/rdonlyres/1D96311C-F90D-4E97-B355DFEA0DD1ABEA/0/TLconsolidado.pdf $>$. Acesso em: 7 mar. 2008. 
PRADO ENRÍQUEZ, Martha Asunción. Nuevas formas societarias en la estructura orgánica del MERCOSUR. derecho societario argentino iberoamericano. In: CONGRESO ARGENTINO DE DERECHO SOCIETARIO, 6.; CONGRESO IBEROAMERICANO DE DERECHO SOCIETARIO Y DE LA EMPRESA, 2., 1995, Buenos Aires. Anales... Coord. Eduardo Favier Dubois e Ricardo Nissen. Buenos Aires: Edit. Ad-Hoc, 1995. p. 731-740.

PROTOCOLO de Defesa da Concorrência para o MERCOSUL. Disponível em: <http:/ /www.cade.gov.br/internacional/Protocolo_Defesa_Concorrencia_Mercosul.pdf >. Acesso em: 9 maio 2008.

SENTENCIA del Tribunal de Justicia de 16 de junio de 1987. Comision de las Comunidades Europeas contra Republica Italiana. Transparencia de las relaciones financieras entre los estados miembros y las empresas publicas. Asunto 118/85. Reconpilación de Jurisprudencia 1987, p. 02599. EurLex, 61985J0118. Disponível em: <http://eur-lex.europa.eu/LexUriServ/ LexUriServ.do?uri=CELEX:61985J0118:ES:HTML>. Acesso em: 10 out. 2007.

SOARES, Guido. Uma revisão em profundidade em 1996 de: As instituições do MERCOSUL e as soluções de litígios no seu âmbito - Sugestões. In: BAPTISTA, Luis Olavo; MERCADANTE DE AZEVEDO, Araminta; CASELlA BORBA, Paulo (Coord.). MERCOSUL, das negociações à implantação. São Paulo: LTr Editora, 1998.

URUGUAI. Ley n. 17.243, de 29 junio de 2000. Política de Competencia Nacional. Diário Oficial, Montevideo, n. 25554, 6 julio 2000. Disponível em: <http://www.parlamento.gub.uy/leyes/AccesoTextoLey.asp?Ley=17243\&Anchor=>. Acesso em: 10 out. 2007.

VERSÃO consolidada do Tratado da União Européia. Jornal Oficial da União Européia [Edição em língua portuguesa], ano 51, n. C115, p. 13-45, 9 maio 2008. Disponível em: <http://eur-lex.europa.eu/LexUriServ/LexUriServ.do?uri= OJ:C:2008:115:0013:0045:PT:PDF>. Acesso em: 10 jun. 2008. 